The alkyl leads (commonly tetraethyl lead and tetramethyl lead in the United Kingdom) and triorthocresyl phosphate along with lead scavengers are added to petroleum as anti-knock agents. These, along with the hexane isomers, are usually assumed to be the main toxic constituents of gasoline. The alkyl leads can be absorbed by inhalation but triorthocresyl phosphate is less volatile. The composition of the gasoline that the child was exposed to in Sudan is not known.

Lead poisoning is more likely to cause a mononeuropathy and the nerve conduction is only slightly reduced. In our patient, however, there was gross slowing of the conduction velocity. Furthermore, lead concentrations, $x$ ray films, and the blood picture was normal. Karani ${ }^{3}$ reported a case of toxic neuropathy in a young man who regularly drank petrol and attributed this to the additive triorthocresyl phosphate ${ }^{3}$ but this substance is unlikely to be absorbed in large quantities by sniffing petrol vapour.

We suggest that the profound motor neuropathy in our patient was probably caused by the $\mathrm{N}$-hexane component of petroleum. ${ }^{4}$ There are many reports of a similar neuropathy occurring in glue sniffers and in workers exposed to industrial sources of $\mathrm{N}$-hexane or petroleum benzine. $\mathrm{N}$-hexane seems to be the main toxic agent in organic solvent mixtures; toluene and other hydrocarbons, though potentially neurotoxic, seem to exert some protective effect against the nerve damage caused by $\mathrm{N}$-hexane. The clinical features depend to some extent on the length and level of exposure. A motor neuropathy is usually the predominant finding, though in some cases there are also some sensory symptoms. Deterioration often continues after exposure has ceased. The motor nerve conduction velocity typically is grossly reduced and histological examination reveals a primary axonal neuropathy with secondary effects on the myelin and pronounced nodal widening. ${ }^{5}$

We thank Professor $\mathrm{H}$ Lambert for referring the patient and Professor R Anderson for helpful advice.

\section{References}

1 CDC. Gasoline sniffing and lead toxicity among siblingsVirginia. MMWR 1985;34:453-5.

2 Kaufman A. Gasoline sniffing among children in a Pueblo Indian village. Pediatrics 1973;51:1060-4.

${ }^{3}$ Karani V. Peripheral neuritis after addiction to petrol. $\mathrm{Br}$ Med J 1966;i:216.

4 Ono Y, Takeuchi Y, Hisanaga N, Iwata M, Kitoh J, Sugiura Y. Neurotoxicity of petroleum benzine compared with $\mathrm{N}$-hexane. Int Arch Occup Environ Health 1982;50:219-29.

5 Cianchetti C, Abbritti G, Perticoni G, Siracusa A, Curradi F. Toxic polyneuropathy of shoe-industry workers. J Neurol Neurosurg Psychiatry 1976;39:1151-61.

Correspondence to Dr D M B Hall, Department of Child Health, St George's Hospital, Cranmer Terrace, London SW17.

Received 13 March 1986

\title{
Hypovitaminosis E induced neuropathy in exocrine pancreatic failure
}

\author{
G DAVIDAI, T ZAKARIA, R GOLDSTEIN, A GILAI, AND S FREIER
}

Department of Pediatrics, Rothschild Hospital, Haifa, and Department of Pediatrics, Gastroenterological Research Laboratories and Institute of Neurophysiology, Shaare Zedek Hospital, Jerusalem, Israel

SUMMARY A 4 year old girl with congenital nerve deafness and pancreatic insufficiency had incapacitating ataxia. Electrophysiological studies of the median nerve and the brain stem evoked response were abnormal. Serum vitamin E concentration was low. After intramuscular injections of vitamin $E$ the ataxia disappeared and electrophysiological variables reverted to normal.

This report describes a 4 year old girl with a variant of the pancreatic deficiency and congenital nerve deafness syndrome. As a consequence of the accompanying malabsorption she had hypovitaminosis $\mathrm{E}$, incapacitating ataxia, and abnormal electrophysiological studies of the nervous system. Treatment with intramuscular vitamin $\mathrm{E}$ resulted in clinical and functional improvement.

\section{Case report}

The patient was a 4 year old girl, the oldest of three sisters born to non-consanguineous Arab parents. Her birth weight was $2700 \mathrm{~g}$. At the age of 1 year she was noticed to be suffering from abdominal distension, frequent loose smelly stools, and failure to gain weight in spite of a ravenous appetite. Early in life she had been found to have impaired hearing, with a resultant delay in speech development. At 13 
months an audiogram showed bilateral severe sensorineural hearing loss. Her motor development was delayed: she could sit and crawl at 1 year, stand by 2 , and walk at $2 \frac{1}{2}$.

On admission her weight was $11 \mathrm{~kg}$, height $85 \mathrm{~cm}$, and head circumference $47 \mathrm{~cm}$ (50th centile for 15 , 18 , and 21 months, respectively). She stood on a wide base and had a grossly unsteady gait and a coarse tremor of her hands. Her tendon reflexes were absent. Routine laboratory investigations yielded normal results. Her serum IgA concentration was raised. Vitamin $\mathrm{E}$ concentrations were $0-0.1 \mathrm{mg} / 100 \mathrm{ml}$ (normal $0.5-1.5 \mathrm{mg} / 100 \mathrm{ml}$ ) and no rise could be obtained after oral administration of vitamin $\mathrm{E}$ in a dose of $100 \mathrm{mg} / \mathrm{kg} /$ day. Serum cholesterol was $54 \mathrm{mg} / 100 \mathrm{ml}$ and the three day stool collection showed an excretion of $21.7 \mathrm{~g}$ fat/day. The sweat test yielded normal results.

A small intestinal biopsy produced normal results by light microscopy. The chest $x$ ray yielded normal results, the wrist $x$ rays showed a bone age compatible with a chronological age of 1.5 years, and there was no evidence of rickets. A barium meal, endoscopic retrograde choledochopancreatography and ultrasonography of the pancreas yielded normal results.

Pancreation function was estimated by duodenal intubation and subsequent intravenous injection of cholecystokinin octapeptide (Kinevac, Squibb Co, New Brunswick, New Jersey, United States). Only small volumes of duodenal juice were obtained after stimulation with cholecystokinin octapeptide, and $\mathrm{pH}$ rose to 6.7. Trypsin remained absent and only minute amounts of lipase and amylase activities could be detected ('Phadebas amylase test', Pharmacia diagnostics, Uppsala, Sweden).

The electrophysiological studies of brain stem and peripheral nerves are presented in the Table. A

Table 1 Electrophysiological studies of the median nerve and brain stem auditory evoked response

\begin{tabular}{llll}
\hline & $\begin{array}{l}\text { Before } \\
\text { treatment }\end{array}$ & $\begin{array}{l}\text { After } \\
\text { treatment }\end{array}$ & Normal \\
\hline Median nerve & & & \\
Distal latency (msec) & $6 \cdot 2$ & $3 \cdot 9$ & $<3 \cdot 6$ \\
Amplitude (mv) & 4 & $6 \cdot 1$ & $>5$ \\
Conduction velocity (msec) & $17 \cdot 8$ & $35 \cdot 2$ & $>32$ \\
F response latency (msec) & 31 & 27 & $<28$ \\
Brain stem auditory evoked response & & & \\
Latency (msec): & $2 \cdot 1$ & 1.6 & $<1.6$ \\
$\quad$ Wave 1 & $3 \cdot 9$ & $3 \cdot 5$ & $<3 \cdot 4$ \\
$\quad$ Wave 3 & $7 \cdot 3$ & 6 & $<6 \cdot 1$ \\
$\quad$ Wave 5 & $5 \cdot 2$ & $4 \cdot 4$ & $\leqslant 4 \cdot 4$ \\
Brain stem transmission time (msec) & $0 \cdot 2$ & $4 \cdot 1$ & \\
Amplitude of wave V (mv) & & & \\
\hline
\end{tabular}

biopsy examination of the sural nerve yielded normal results.

A diagnosis of pancreatic insufficiency was made and treatment with pancreatic enzyme supplements (Viokase $^{\mathrm{R}}$, AH Robbins, Monticello, Illinois, United States) was begun. Within one month she gained $2.5 \mathrm{~kg}$ in weight. Daily intramuscular injections of $100 \mathrm{mg}$ vitamin E (Evitol, Hoffman La Roche, Basel) were given for 14 days.

After two months her gait became steady, the tremor disappeared, the deep reflexes returned, and her behaviour became sociable. Her serum vitamin E concentration rose to $1.7 \mathrm{mg} / 100 \mathrm{ml}$, and the pronounced improvement in the electrophysiological studies is shown in the Table.

\section{Discussion}

Our patient suffered from exocrine pancreatic insufficiency and a sensory-neural defect of hearing. This combination of clinical features has been described previously by several authors. ${ }^{12}$ Our patient differed from them in that other features of this syndrome were not found. Cystic fibrosis was excluded by a normal sweat test and Schwachman's syndrome by normal skeletal $x$ rays and blood picture.

Clinically, the most important feature of our patient was the early onset of tremor, ataxia, and absent tendon reflexes, presumably due to hypovitaminosis $\mathrm{E}$. In pancreatic insufficiency low vitamin $\mathrm{E}$ concentrations can be found in early childhood, ${ }^{3}$ but neurological signs have not, so far, been found before the age of 10 years. ${ }^{4}$ Large oral doses of vitamin $\mathrm{E}$, of the order of $100 \mathrm{mg} / \mathrm{kg}$, are usually capable of restoring normal body stores of this vitamin. Our patient did not respond to oral treatment but required intramuscular treatment.

Electrophysiological studies have been reported by a number of authors, some of whom noticed improvement after treatment with vitamin E. ${ }^{56}$ With this treatment there was not only pronounced and rapid clinical improvement, but we could show reversion to normal or near normal values of her median nerve distal latency, amplitude, conduction velocity, and brain stem evoked responses.

This case shows that in pancreatic insufficiency lack of vitamin $E$ with its associated nervous damage may occur early in life. The implications for children with cystic fibrosis are obvious. While borderline or low concentrations of vitamin $E$ are often found in cystic fibrosis, tremor, weakness, and absent tendon reflexes may be wrongly ascribed to the basic disease and malnutrition rather than to vitamin $\mathrm{E}$ deficiency. Electrophysiological studies such as were performed in this patient may help to diagnose the 
effects of vitamin $E$ induced neurologic dysfunction. In addition, electrophysiological studies may be a good variable to measure the effects of treatment.

This research was supported by the Lori and Bernard Levmore Research Fund.

\footnotetext{
References

1 Johanson A, Blizzard R. A syndrome of congenital aplasia of the alae nasi, deafness, hypothyroidism, dwarfism, absent permanent teeth and malabsorption. $J$ Pediatr 1971;79:982-7.

2 Townes PL, White MR. Identity of two syndromes. Proteolytic lipolytic and amylocytic deficiency of the exocrine pancreas with congenital anomalies. Am J Dis Child 1981;135:248-50.

${ }^{3}$ Farrell P, Bieri JG, Fretantoni JF, Wood RE, di Sant Agnese P.
}

The occurrence and effects of human vitamin E deficiency. J Clin Invest 1977;60:233-41.

${ }^{4}$ Bye AME, Muller DPR, Wilson J, Wright VH, Mearns MB. Symptomatic vitamin E deficiency in cystic fibrosis. Arch Dis Child 1985;60:162-4.

5 Muller DPR, Lloyd JK, Bird AC. Long term management of A- $\beta$-lipoproteinemia: possible role for vitamin E. Arch Dis Child 1977;52:209-14

${ }^{6}$ Harding AE, Muller DPR, Thomas PK, Willison HJ. Spinocerrebellar degeneration secondary to chronic intestinal malabsorption: a vitamin E deficiency syndrome. Ann Neurol 1982;12:419-24.

Correspondence to Dr S Freier, Shaare Zedek Hospital, Jerusalem, Israel.

Received 8 May 1986

\title{
Recurrent sepsis and gastrointestinal ulceration due to child abuse
}

\author{
L G RUBIN, A ANGELIDES, M DAVIDSON, AND P LANZKOWSKY
}

Department of Pediatrics, Schneider Children's Hospital of Long Island Jewish Medical Center and Health Sciences Center, State University of New York at Stony Brook, United States of America

SUMMARY An 11 year old girl developed progressive upper gastrointestinal ulceration and recurrent episodes of intravenous catheter associated polymicrobial septicaemia. Evaluation failed to establish a cause. After exclusion of the parents and careful surveillance of the patient she improved, supporting the diagnosis of suspected child abuse (a form of Meadow's syndrome).

Meadow's syndrome (Munchausen's syndrome by proxy) is a form of child abuse in which a parent feigns illness in his or her child. ${ }^{1}$ In a variant form the parent actually induces illness in the child. The diagnosis is confirmed by surreptitious observations ${ }^{2}$ confrontation of the parents and admission of guilt, ${ }^{3}$ and/or selected laboratory tests. ${ }^{4}$ This paper reports a girl with recurrent septicaemia and gastrointestinal ulceration of unknown aetiology who progressively deteriorated over a period of one year. She improved after exclusion of her parents and constant surveillance.

\section{Case report}

An 11 year old girl weighing $39 \mathrm{~kg}$ developed fever, cough, and protracted vomiting in January 1983, two months after a gastric ulcer had been diagnosed in her 14 year old brother. During a five week admission to hospital she had persistent vomiting and intermittent diarrhoea. She was transferred to Schneider Children's Hospital where examination revealed a thin, mildly dehydrated child weighing $33.8 \mathrm{~kg}$ who was otherwise normal.

Laboratory evaluation showed a haemoglobin concentration of $12.6 \mathrm{~g} / \mathrm{dl}$ and serum protein concentration of $5.9 \mathrm{~g} / 100 \mathrm{ml}$. The following tests yielded normal or negative results: leucocyte count and differential, erythrocyte sedimentation rate, serum albumin, serum electrolyte, and immunoglobulin concentrations, urinalysis, stool culture, three stool examinations for ova and parasites, chest radiography, and barium contrast studies of the upper and lower gastrointestinal tracts, including views of the terminal ileum. Upper gastrointestinal endoscopy revealed a solitary lesser curve gastric ulcer. Cimetidine and antacids were administered with satisfactory clinical response.

Five days after discharge she developed a recurrence of abdominal pain and intractable vomiting and complained of a sore throat. On re-admission physical examination was remarkable for an erythematous pharynx and a tongue ulcer. Repeat endoscopic examination 20 days after the first revealed persistence of the gastric ulcer and a new deep $2 \mathrm{~cm}$ ulcer of the distal oesophagus. Serum amylase and gastrin activities were normal as was a secretin stimulation study. Sucralfate was added to the regimen and the cimetidine increased. After discharge episodes of vomiting and abdominal pain 